\title{
Hypertrophic cardiomyopathy in a 20-year-old woman
}

\author{
E.O.F. van Gorselen · R. Schuurman · W. Terpstra
}

Published online: 26 February 2015

(C) The Author(s) 2015. This article is published with open access at Springerlink.com

A case of a young woman with complaints of shortness of breath and recurrent collapses is presented, including echocardiographic and cardiac MRI images showing extremely hypertrophied myocardium due to hypertrophic cardiomyopathy. The patient was referred for therapy and genetic counselling.

Keywords Hypertrophic cardiomyopathy .

Echocardiography $\cdot$ Cardiac magnetic resonance

imaging $\cdot$ Cardiac surgery $\cdot$ ICD therapy $\cdot$ Genetics

A 20-year-old woman was seen with palpitations, collapses and shortness of breath. Her father died at the age of 33 years. Echocardiography showed an extremely hypertrophied interventricular septum (Fig. 1a-d). The typical dagger shape seen upon Doppler imaging displays a maximum pressure gradient of $41 \mathrm{mmHg}$ at rest. A septal thickness of $42 \mathrm{~mm}$ was measured on cardiac magnetic resonance imaging (Fig. 1e-h). No systolic anterior movement of the mitral valve was appreciated. Late gadolinium enhancement

E.O.F. van Gorselen $(\bowtie) \cdot$ W. Terpstra

Department of Cardiology, Slingeland Hospital,

Kruisbergseweg 25,

7000 AD Doetinchem, The Netherlands

e-mail: e.gorselenvan@slingeland.nl

W. Terpstra

e-mail: w.terpstra@slingeland.nl

R. Schuurman

Department of Cardiology, Medisch Spectrum Twente,

Haaksbergerstraat 55,

7513 ER Enschede, The Netherlands

e-mail: r.schuurman@mst.nl showed mild intramural contrast enhancement of the basal septal region. Holter registration showed periods of nonsustained ventricular tachycardia. The patient underwent implantable cardioverter-defibrillator placement and septal myectomy [1]. At genetic counselling a mutation was found in the MYBPC3 gene. Hypertrophic cardiomyopathy is the most common hereditable cardiovascular disorder with an estimated prevalence of $0.2 \%$ [2]. The pattern of inheritance is autosomal dominant. It is the most common cause of sudden cardiac death in young individuals.

Funding None.

Conflict of interest No conflicts of interest.

Open Access This article is distributed under the terms of the Creative Commons Attribution License which permits any use, distribution, and reproduction in any medium, provided the original author(s) and the source are credited.

\section{References}

1. Maron BJ, Maron MS. Hypertrophic cardiomyopathy. Lancet 2013;381(9862):242-55.

2. Michels M, Hoedemaekers YM, Kofflard MJ, et al. Familial screening and genetic counselling in hypertrophic cardiomyopathy: the Rotterdam experience. Neth Heart J 2007;15(5):184-90. 

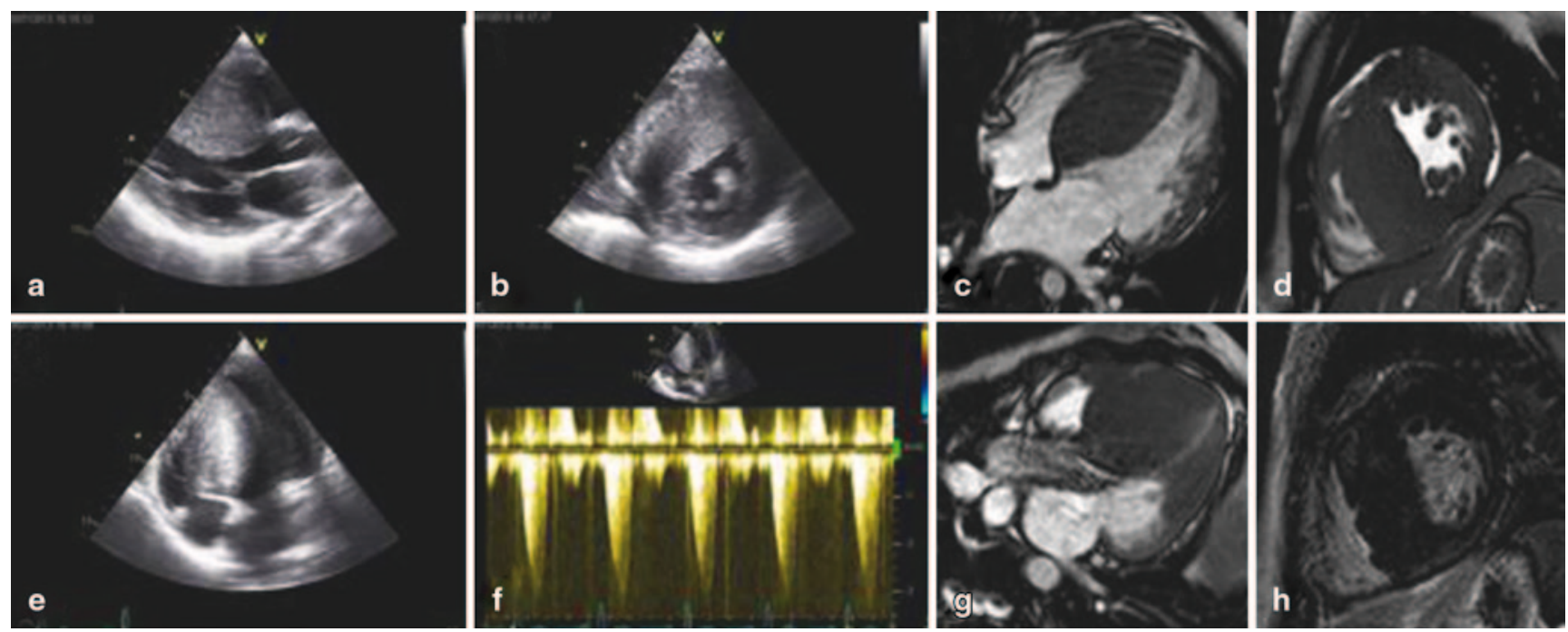

Fig. 1 Echocardiography: parasternal long axis (a), parasternal short axis (b), apical 4-chamber view (c) and continuous wave Doppler of the outflow tract region (d), Cardiac MRI: cine image horizontal long axis view (e), short axis view (f), LVOT view (g) and LGE short axis view (h) 